\title{
KAJIAN ASPEK KESELAMATAN KERJA PADA KAPAL PAJEKO DI PANGKALAN X DAN Y KEPULAUAN SANGIHE
}

\author{
A Study on Occupational Safety Aspects of Mini Purse Seiner of X and Y Stations in \\ Sangihe Islands
}

\author{
Fitria Fresty Lungari, Mukhis Abdul Kaim \\ Teknologi Penangkapan Ikan, Politeknik Negeri Nusa Utara \\ Jl. Kesehatan, No. 1 Kelurahan Sawang Bendar Kecamatan Tahuna, 95812 \\ Email: fitria7ungari@gmail.com
}

\begin{abstract}
Abstrak: Pekerjaan nelayan di kapal penangkap ikan merupakan pekerjaan berisiko tinggi dalam hal kecelakaan akibat kerja ataupun penyakit akibat kerja. Dalam upaya melindungi dan menjamin keselamatan, keamanan dan kenyamanan kerja awak kapal perikanan, maka faktor keselamatan operasional kapal perikanan di laut sangatlah penting, terutama kondisi dan ketersediaan alat keselematan kapal dan kelaikannya, sehingga bila terjadi kecelakaan alat keselamatan kerja di kapal siap digunakan. Dalam penelitian ini, implementasi peraturan pengawakan dan keselamatan kerja di kapal pukat cincin (purse seine) atau pajeko dianalisa dengan pendekatan check list terhadap peraturan yang berlaku sedangkan untuk tingkat pemahaman awak kapal tentang pengawakan dan keselamatan kerja akan dihitung dengan menggunakan pengkategorian sederhana pada tingkat kesadaran nelayan terhadap pentingnya aspek keselamatan kerja dilakukan dengan pendekatan pengkategorian menggunakan standar deviasi dari jumlah isian dengan bantuan software microsoft excel. Untuk mengetahui kategori rendah, sedang dan tingginya pemahaman nelayan, fungsi IF pada microsoft excel digunakan. Hasil menunjukan bahwa hanya 1 orang nahkoda yang memiliki ANKAPIN II (Ahli Nautika Penangkap Ikan) sedangkan yang lain hanya memiliki sertifikat SKK dan surat keterangan dari pemerintah setempat. Tingkat pemahaman nelayan juga bervariasi yakni $(11,13$ dan 6) nelayan di pangkalan $X$ dan (6,13 dan 11) nelayan di pangkalan $\mathrm{Y}$ dengan tingkat pemahaman tinggi, sedang dan rendah berturut-turut. Jadi, secara keseluruhan penerapan regulasi belum dilakukan secara maksimal dan pemahaman nelayan tentang pentingnya aspek keselamatan masih kurang. Penelitian ini mewakili laporan yang belum banyak dikaji tentang impelementasi dan pemahaman aspek keselamatan kerja pada pajeko-pajeko maupun awaknya, khususnya di pangkalan-pangkalan di Kabupan Sangihe, informasi amat krusial untuk evaluasi bagi semua stakeholder.
\end{abstract}

Kata kunci: pajeko, sangihe, aspek keselamatan

\begin{abstract}
Fishing boat deckhand is a high-risk job in terms of occupational accidents or diseases. In an effort to protect and ensure safetiness, security and work comfort of fishing boat crews, our study focuses on operational safety factors on fishing vessels. In particular, key factors relate to the availability and wellmentained condition of the safety instruments that in case of an accident, they would be operational. This study aimed to analyse the implementation of manning and work safety regulation aspects and ship's crews level of understanding of these aspects by using a check list approach and simple categorization against the existing regulations respectively. A categorization approach was carried out using a standard deviation of the number of entries with the help of Microsoft Excel to measure the implementation aspects and IF function in Microsoft Excel was used to measure the level of understanding of fishermen on those aspects. The results showed only 1 captain had ANKAPIN II (Fishing Ship Nautical Expert), whereas others earned only SKK certificate and/or local government's certificate. Fishermen' understanding of the safety aspects varied between $(11,13 \& 6)$ fisheremen in station $X$ and $(6,13 \& 11)$ fishemen in station $Y$ with high, medium and low level of understanding of the occupational safety aspects respectively. Overall, occupational safety aspects were not fully implemented and pursier's crews level of understanding on these crucial aspects was lacking. This study represents few reports on implementation of occupational safety aspects in purseiners in Sangihe Islands, giving crucial insight for evaluation to all stakeholders.
\end{abstract}

Keyword: pajeko, sangihe, safety aspects 


\section{PENDAHULUAN}

Undang-undang Perikanan Nomor 45 Tahun 2009 mendefinisikan kapal perikanan sebagai kapal, perahu, atau alat apung lainnya yang digunakan untuk berbagai kegiatan perikanan seperti operasi penangkapan, budidaya, pengangkutan dan pengolahan ikan, pelatihan perikanan maupun penelitian/eksplorasi perikanan.

Dalam proses pemanfaatan sumberdaya perikanan, bidang perikanan tangkap umumnya terdiri dari kapal ikan, alat tangkap, metode dan nelayan, empat kunci keberhasilan suatu usaha penangkapan ikan di laut.

Penangkapan ikan secara teknis mewakili salah satu aktivitas di laut yang tergolong memiliki resiko atau tingkat bahaya lebih tinggi daripada pekerjaan lain. Hal ini sejalan dengan karakteristik pekerjaan nelayan penangkap ikan menurut FAO (2007), yaitu berbahaya, kotor dan sulit. Secara langsung, kondisi ini menuntut kecakapan dan kemampuan awal kapal saat bekerja berdasarkan pembagian kerja di atas kapal ikan.

Peraturan Menteri Kelautan dan Perikanan Republik Indonesia Nomor 42/Permen-Kp/2016 Tentang Perjanjian Kerja Laut Bagi Awak Kapal Perikanan, menjelaskan bahwa awak kapal perikanan (fisher) adalah setiap orang yang dipekerjakan di kapal Perikanan untuk kegiatan usaha perikanan tangkap.

Purse seiner atau pukat cincin merupakan salah satu jenis kapal perikanan yang digunakan untuk menangkap ikan-ikan yang bergerombol, dengan menggunakan alat tangkap pukat cincin. Di kepulauan Sangihe, masyarakat menyebutnya pajeko. Penelitian ini mengkaji aspek terkait keselamatan kerja termasuk peralatan navigasi, peralatan keselamatan perorangan, peralatan kesehatan, perlengkapan kerja dan peralatan kerja. Tujuan studi ini adalah untuk mengetahui sejauh mana kesesuaian yang sudah dijalankan di dua pangkalan kapal pajeko yang ada di kepulauan Sangihe.

\section{Aturan Sertifikasi Awak Kapal Perikanan}

Peraturan Pemerintah RI Nomor 07 Tahun 2000 menjelaskan tentang kepelautan, dimana dokumen pengawakan kapal terdiri dari perjanjian kerja laut, sijil awak kapal, buku pelaut, sertifikat kompetensi dan sertifikat keahlian yang sesuai dengan jabatan di atas kapal.

Menurut Kepmenhub No.9 Tahun 2005 tentang Pendidikan dan Latihan, Ujian serta Sertifikasi Pelaut Kapal Penangkap Ikan, sertifikat keahlian (Certificate of Proficiency/COP) awak kapal perikanan terdiri dari Ahli Nautika Kapal Penangkap Ikan (ANKAPIN) untuk perwira dek dan Ahli Teknika Kapal Penangkap Ikan Tingkat (ATKAPIN) untuk perwira mesin. Standar uji mutu sertifikat tersebut mengacu pada peraturan international Standart Training of Certificate Watchkeeping-Fisheries (STCW-F) 1995 dari International Maritim Organozation (IMO). Adapun tingkatan sertifikat keahlian/ kompetensi kepelautan bagian dek dan mesin masing-masing terdiri dari 3 (tiga), yaitu:

1) Kapal 30 - 60 GT, COP Nahkoda ANKAPIN III, KKM ATKAPIN III.

2) Kapal 60 - 88 GT, COP Nahkoda ANKAPIN II, KKM ATKAPIN II.

3) Kapal > 88 GT, COP Nahkoda ANKAPINI, KKM ATKAPIN I.

Berdasarkan ukuran Panjang kapalnya, kewenangan pengawakan kapal penangkap ikan dikelompokan menjadi 3 yaitu :

1) Kapal panjang $<12 \mathrm{~m}$, COP Nahkoda ANKAPIN III, KKM ATKAPIN III.

2) Kapal panjang $12-24 \mathrm{~m}, \mathrm{COP}$ Nahkoda ANKAPIN II, KKM ATKAPIN II.

3) Kapal panjang $>24 \mathrm{~m}$, COP Nahkoda ANKAPIN I, KKM ATKAPIN I

Berdasarkan wilayah operasinya, kewenangan pengawakan kapal penangkap ikan dikelompokkan menjadi 3 yaitu :

1) Wilayah operasi perairan $<60$ Mil dan tidak termasuk ZEE Indonesia, COP Nahkoda ANKAPIN III, KKM ATKAPIN III. 
2) Wilayah operasi $>60$ mil dan tidak termasuk ZEE Indonesia, COP NahkodaANKAPIN II, KKM ATKAPIN II.

3) Wilayah operasi ZEE Indonesia, COP Nahkoda ANKAPIN I, KKM ATKAPINI.

Budiman (2016), dalam kajiannya menyebutkan bahwa sertifikat keterampilan (Certificate of Competency/COC) awak kapal penangkap ikan terdiri dari: Basic Safety Training for all fishing vessel personal (BST-F), Advance FireFigthing (AFF), Medical Emergency First Aid (MEFA), Medical Care on Board (MC), Radar Simulator, General Maritim Distress and Safety System (GMDSS, Survival Craft and Rescue Boat (SCRB), Shif Security Officer (SSO), Electronic Chart Display and Information System (ECDIS).

\section{Kapal Mini Purse Seiner di Pangkalan X dan Y}

Kapal pukat cincin (mini purse seiner) masuk dalam kategori pengunaan metode penangkapan ikan jenis encircling gear atau pengoperasian alat tangkap dengan melingkari gerombolan ikan. Turning ability yang baik, stabilitas kapal yang tinggi, tahanan yang rendah dan lebar kapal yang memadai menjadi syarat untuk kapal pukat cincin ini. Jenis kapal purse seine yang ada di kabupaten kepulauan Sangihe umumnya merupakan jenis kapal yang berukuran kecil (mini purse seiner). Bentuk kapal yang ada di dua pangkalan memilik perbedaan pada bagian super structure dimana untuk pangkalan $\mathrm{X}$ umunya memiliki bangunan yang terbuka dengan atap yang memanjang dari bagian haluan ke bagian buritan (Gambar 1 a), sedangkan untuk kapal yang ada di pangkalan Y (Gambar $1 \mathrm{~b}$ ) bangunan di atas kapal umumnya merupakan bangunan yang memiliki ruang tertutup dengan bentuk penataan ruang navigasi yang lebih baik. Untuk tipe $\mathrm{X}$ menggunakan motor tempel dan tipe $\mathrm{Y}$ menggunakan mesin.

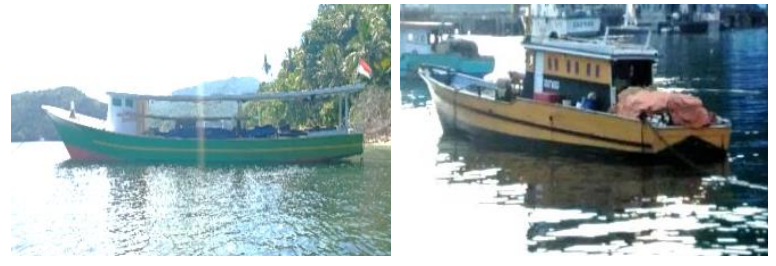

Gambar 1 a. Kapal pajeko di pangkalan X, b. kapal pajeko di pangkalan $\mathrm{Y}$

Ukuran utama 10 unit purse seiner yang ada di pangkalan X dan Y memiliki panjang 13,85 m sampai dengan $23 \mathrm{~m}$, lebar $3.80 \mathrm{~m}$ sampai dengan $5 \mathrm{~m}$, dan dalam $0.7 \mathrm{~m}$ sampai dengan $3 \mathrm{~m}$. Sehingga ke 10 unit purse seiner ini masuk dalam kategori kapal berukuran di bawah dari $24 \mathrm{~m}$.

\section{METODE PENELITIAN}

Metode yang digunakan dalam peneltian ini yaitu metode deskriptif, dimana prosesnya dengan melakukan survei yang bertujuan memperoleh faktafakta dan gejala-gejala yang ada dan mencari keterangan yang faktual. Pada tingkat kesadaran nelayan terhadap pentingnya aspek keselamatan kerja, dilakukan dengan pendekatan pengkategorian menggunakan standar deviasi dari jumlah isian dengan bantuan software Microsoft excell. Adapun pengkategorian skor total yaitu $\mathrm{X}<\mathrm{M}$ - 1 SD (starndar deviasi) = rendah, M- 1SD $<=\mathrm{X}<\mathrm{M}+1 \mathrm{SD}=$ sedang dan jika $\mathrm{M}+1 \mathrm{SD}<=\mathrm{X}$ maka masuk kategori termasuk tinggi.

\section{HASIL DAN PEMBAHASAN}

Berdasarkan ukuran utama kapal yang diamati, maka penerapan regulasi yang menjadi rujukkan yaitu berkaitan dengan ukuran panjang kapal (LOA) < $24 \mathrm{~m}$. Hasil pengamatan di lapangan pada 10 unit purse seiner, diperoleh jenis sertifikasi yang dimiliki nahkoda, kepala kamar mesin (KKM) dan anak buah kapal (ABK), yang ditunjukkan pada Tabel 1 berikut ini. 
Tabel 1. Sertifikasi crew purse seiner

\begin{tabular}{|c|c|c|c|c|c|}
\hline \multirow[t]{2}{*}{ No } & \multirow{2}{*}{$\begin{array}{l}\text { Nama } \\
\text { Kapal }\end{array}$} & \multirow{2}{*}{$\begin{array}{c}\text { Panjang } \\
\text { (LoA) }\end{array}$} & \multicolumn{3}{|c|}{ Crew purse seiner } \\
\hline & & & Nahkoda & KKM & $\mathrm{ABK}$ \\
\hline \multicolumn{6}{|c|}{$\mathrm{X}$} \\
\hline 1 & KM 1 & $22 \mathrm{~m}$ & - & - & - \\
\hline 2 & KM 2 & $17 \mathrm{~m}$ & - & - & - \\
\hline 3 & KM 3 & $21 \mathrm{~m}$ & SKK & - & - \\
\hline \multicolumn{6}{|c|}{$\mathrm{Y}$} \\
\hline 4 & $\mathrm{KM}$ a & 16,63 & $\begin{array}{l}\text { SKK, BST } \\
\text { dan MFA }\end{array}$ & SKK & - \\
\hline 5 & $\mathrm{KM} \mathrm{b}$ & $13,85 \mathrm{~m}$ & SKK, BST & SKK & - \\
\hline 6 & KM c & $22,70 \mathrm{~m}$ & SKK & SKK & - \\
\hline 7 & KM d & $21 \mathrm{~m}$ & $\begin{array}{l}\text { ANKAPIN } \\
\text { II, BST }\end{array}$ & SKK & - \\
\hline 8 & $\mathrm{KM} \mathrm{e}$ & $21 \mathrm{~m}$ & SKK, BST & $\begin{array}{l}\text { SKK, } \\
\text { BST }\end{array}$ & \\
\hline 9 & KM f & $23 \mathrm{~m}$ & SKK & SKK & - \\
\hline 10 & KM g & $21 \mathrm{~m}$ & SKK & SKK & - \\
\hline
\end{tabular}

Keterangan:

\begin{tabular}{|c|c|}
\hline SKK & $\begin{aligned}= & \text { Surat Ketrampilan dan Kecakapan } \\
& \text { Melaut (60 mil) }\end{aligned}$ \\
\hline BST & $=$ Basic Savety Trainning \\
\hline ANKAPIN & $=$ Ahli Nautika Kapal Penangkap Ikan \\
\hline MFA & $=$ Medical First Aid \\
\hline
\end{tabular}

Berdasarkan data pada Tabel 1, penerapan regulasi pengawakan berdasarkan ukuran kapal $<24 \mathrm{~m}$ yang ada di purse seiner pangkalan $\mathrm{X}$ masih belum dilakukan, hal ini terlihat yaitu nahkoda dan KKM tidak memiliki ANKAPIN II dan ATKAPIN II, dan ABK juga tidak memiliki sertifikat kepelautan seperti yang disyaratkan. Berdasarkan hasil wawancara di lapangan, pemahaman nelayan akan regulasi pengawakan masih sangat minim. Selain itu, konstruksi kapal dan jenis mesin motor tempel yang digunakkan menjadi salah satu pertimbangan nelayan tidak melakukan pengurusan persuratan yang diwajibkan. Nelayan hanya memiliki surat keterangan pengawakan yang dikeluarkan oleh dinas perhubungan daerah, tanpa dilengkapai pelatihan keahlian tertentu dan hanya mengandalkan pengalaman kerja yang sudah ada.

Penerapan regulasi pengawakan di pangkalan $\mathrm{Y}$ sudah ada, namun umumnya sertifikat yang dimiliki Nahkoda dan KKM hanya sebatas SKK 30/60 mil yang biasa diperoleh dengan mengikuti pelatihan dari dinas terkait selam 2-3 hari. Kapal-kapal penangkap ikan ini memiliki wilayah operasi perairan $<60$ mil, tidak termasuk ZEEI seharusnya memiliki ANKAPIN II dan ATKAPIN II. Namun hanya 1 kapal yaitu KM d, nahkodanya sudah memiliki ANKAPIN II. Beberapa ABK hanya memiliki sertifikat BST dan pelatihan pengenalan tentang pengawakkan singkat dari beberapa lembaga atau dinas yang berkaitan.

Berdasarkan hasil wawancara, faktor lain yang mempengaruhi kurangnya kompetensi pengawakan yang dimiliki diakibatkan jenis pelatihan yang ada membutuhkan biaya yang mahal serta faktor ketidaktahuan cara maupun tempat untuk pengambilan keahlian tersebut. Hal ini tentunya secara langsung mempengaruhi penerapan regulasi pengawakkan pada kapal-kapal pajeko yang ada di kepulauan Sangihe.

\section{Aspek Keselamatan Kerja di Atas Kapal Purse Seiner}

Hasil pengecekkan secara langsung di lapangan menunjukkan adanya ketidaksesuaian antara peraturan tentang perlengkapan keselamatan standar dengan kondisi keberadaan perlengkapan 3 kapal di pangkalan $\mathrm{X}$ yang diamati, seperti yang ditunjukkan pada Tabel 2.

Tabel 2. Alat Keselamatan Kerja di Kapal pajeko (X)

\begin{tabular}{|c|c|c|c|c|}
\hline \multirow[b]{2}{*}{ No } & \multirow[b]{2}{*}{ Jenis Perlengkapan } & \multicolumn{3}{|c|}{ Kapal } \\
\hline & & $\begin{array}{c}\mathrm{KM} \\
\mathbf{1}\end{array}$ & $\begin{array}{c}\text { KM } \\
2\end{array}$ & $\begin{array}{c}\mathbf{K M} \\
\mathbf{3}\end{array}$ \\
\hline \multirow[t]{5}{*}{1} & Peralatan Navigasi & & & \\
\hline & -Kompas & 1 & 2 & 1 \\
\hline & -GPS & T.A & T.A & T.A \\
\hline & -Radio & T.A & T.A & T.A \\
\hline & -Bendera Negara & 1 & 1 & 1 \\
\hline \multirow[t]{6}{*}{2} & $\begin{array}{l}\text { Keselamatan } \\
\text { Perorangan }\end{array}$ & & & \\
\hline & -Life Jacket & 4 & T.A & 16 \\
\hline & -life Buoy & T.A & T.A & T.A \\
\hline & -Ban dalam & T.A & T.A & T.A \\
\hline & -Sekoci/perahu/rakit & T.A & T.A & 1 \\
\hline & -APAR & T.A & T.A & T.A \\
\hline 3 & Kesehatan (P3K) & T.A & T.A & T.A \\
\hline \multirow[t]{5}{*}{4} & Perlengkapan Kerja & & & \\
\hline & -Kacamata Kerja & T.A & T.A & T.A \\
\hline & -Sarung Tangan & 7 & T.A & 16 \\
\hline & -Sepatu Kerja & T.A & T.A & T.A \\
\hline & -Helm & T.A & T.A & T.A \\
\hline \multirow[t]{6}{*}{5} & Peralatan Kerja & & & \\
\hline & -Derek & 1 & 1 & 1 \\
\hline & -Perkakas: & & & \\
\hline & 1. Obeng & 1 & 1 & 1 \\
\hline & 2. Tang & 1 & 1 & 1 \\
\hline & 3. Kunci mesin & 15 & 7 & 8 \\
\hline \multicolumn{5}{|c|}{ Keterangan: $\mathrm{T} . \mathrm{A}=$ Tidak ada } \\
\hline
\end{tabular}


Menurut hasil wawancara terhadap pemilik kapal dan ABK, ketidaktersediaannya alat keselamatan di kapal mini purse seine (pajeko) di pangkalan $\mathrm{X}$, disebabkan karena daerah penangkapan ikan yang tidak terlalu jauh dari pantai sehingga mereka tidak terlalu mementingkan peralatan keselamatan kerja tersebut. Waktu untuk pergi ke fishingground sampai kembali lagi ke fishing base hanya memakan waktu kurang lebih 4 jam. Kondisi ini dianggap tidak menimbulkan bahaya atau kecelakaan keja. Berkaitan dengan sertifikasi yang dimiliki oleh nelayan, dasar pemahaman tentang aspek keselamatan hanya dapat dilihat dari sudut pandang pengalaman keseharian melaut dan bukan berdasarkan regulasi atau aturan yang berlaku.

Tabel 3.Aspek Keselamatan Kerja di Kapal pajeko (Y)

\begin{tabular}{|c|c|c|c|c|c|c|c|c|}
\hline \multirow[b]{2}{*}{ No } & \multirow{2}{*}{$\begin{array}{c}\text { Jenis } \\
\text { Perlengkapan }\end{array}$} & \multicolumn{7}{|c|}{ Kapal } \\
\hline & & $\begin{array}{c}\text { KM } \\
\mathbf{a}\end{array}$ & $\begin{array}{c}\text { KM } \\
\text { b }\end{array}$ & $\begin{array}{c}\text { KM } \\
\text { c }\end{array}$ & $\begin{array}{c}\text { KM } \\
\text { d }\end{array}$ & $\begin{array}{c}\text { KM } \\
\text { e }\end{array}$ & $\begin{array}{c}\text { KM } \\
\text { f }\end{array}$ & $\begin{array}{c}\text { KM } \\
\mathrm{g}\end{array}$ \\
\hline \multirow[t]{6}{*}{1} & Peralatan Navigasi & & & & & & & \\
\hline & -Kompas & 1 & 1 & 1 & 1 & 1 & 1 & 1 \\
\hline & -GPS & 1 & 1 & 1 & 1 & 1 & 1 & 1 \\
\hline & -Radio & 1 & 1 & 1 & 1 & 1 & 1 & 1 \\
\hline & -Bendera Negara & 1 & 1 & 1 & 1 & 1 & 1 & 1 \\
\hline & -Peta Laut & TA & $\mathrm{TA}$ & TA & TA & 1 & 1 & TA \\
\hline \multirow[t]{6}{*}{2} & $\begin{array}{l}\text { Keselamatan } \\
\text { Perorangan }\end{array}$ & & & & & & & \\
\hline & -Life Jacket & 18 & 17 & 25 & 10 & 20 & 20 & 10 \\
\hline & \begin{tabular}{|l|}
-life Buoy \\
\end{tabular} & - & 3 & 2 & - & 2 & 4 & 2 \\
\hline & -Ban dalam & - & - & - & - & - & - & - \\
\hline & -Sekoci/perahu/rakit & 1 & 1 & 1 & 1 & 1 & 1 & 1 \\
\hline & $\begin{array}{l}\text {-APAR (Alat } \\
\text { Pemadam Api } \\
\text { Ringan) } \\
\end{array}$ & 1 & - & 2 & 1 & 2 & 2 & 2 \\
\hline \multirow[t]{2}{*}{3} & Kesehatan & & & & & & & \\
\hline & Kotak P3K & 1 & 1 & 1 & 1 & 1 & 1 & 1 \\
\hline \multirow[t]{5}{*}{4} & Perlengkapan Kerja & & & & & & & \\
\hline & -Kacamata Kerja & 2 & 2 & 2 & 2 & 2 & 3 & 2 \\
\hline & -Sarung Tangan & 18 & & 25 & 18 & 15 & 10 & 10 \\
\hline & -Sepatu Kerja & $\mathrm{TA}$ & & $\mathrm{TA}$ & $\mathrm{TA}$ & 2 & $\mathrm{TA}$ & TA \\
\hline & -Helm & $\mathrm{TA}$ & & TA & TA & $\mathrm{TA}$ & TA & TA \\
\hline \multirow[t]{6}{*}{5} & Peralatan Kerja & & & & & & & \\
\hline & -Derek & 1 & & 1 & 1 & 1 & 1 & 1 \\
\hline & -Perkakas: & & & & & & & \\
\hline & 1. Obeng & 2 & 1 & 2 & 2 & 3 & 2 & 2 \\
\hline & 2. Tang & 2 & 1 & 2 & 2 & 1 & 1 & 1 \\
\hline & 3. $\begin{array}{l}\text { Kunci } \\
\text { mesin }\end{array}$ & 3 & 3 & 3 & 2 & 3 & 2 & 4 \\
\hline & & 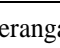 & T. & Tid & & & & \\
\hline
\end{tabular}

Di Pangkalan Y (Tabel 30, jumlah peralatan navigasi untuk 7 unit kapal sudah terpenuhi dengan adanya GPS, Radio, kompas, dan bendera negara. Untuk peta laut sendiri hanya 2 kapal yang ada. Faktor kearifan lokal terkait daerah penangkapan ikan yang masih menggunakan sistem penanda atau yang lebih dikenal dengan sebutan 'tiala' menjadikan fungsi peta laut jarang digunakan. Selain harga yang relatif mahal, daerah pengoperasian pukat cincin (pajeko) yaitu berkisar antara 30-60 mil laut tidak termasuk ZEEI. Adapun aspek keselamatan kerja di atas kapal pajeko pangkalan Y.

\section{Tingkat Kesadaran Crew Kapal Pajeko}

Hasil analisis menunjukkan bahwa dari keseluruhan crew kapal, umumnya tingkat kesadaran akan pentingnya aspek keselamatan kerja di atas kapal masih dikatakan sedang, hal ini karena sebagian besar nelayan belum memahami dan mengerti arti penting tentang aspek keselamatan kerja di kapal (Gambar 2 dan 3).

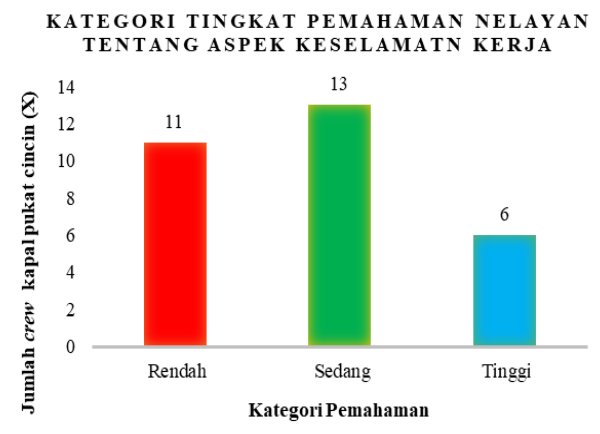

Gambar 2. Diagram Kategori Tingkat Pemahaman Nelayan X tentang Aspek Keselamatan Kerja

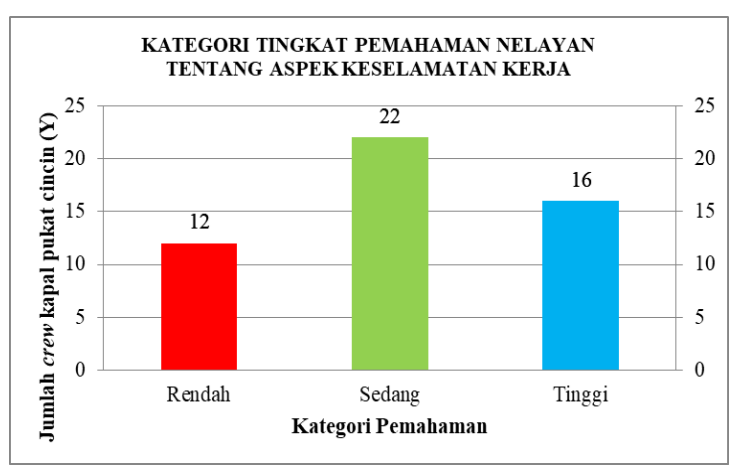

Gambar 3. Diagram Kategori Tingkat Pemahaman Nelayan Y tentang Aspek Keselamatan Kerja 
Pemahaman nelayan terhadap aspek keselamatan kerja untuk kategori ukuran rendah di pangkalan $\mathrm{X}$ yaitu sebanyak 11 orang, sedang 13 orang dan tinggi sebanyak 6 orang (Gambar 2), sedangkan pangkalan Y ukuran rendah 12 orang, sedang 22 orang dan tinggi 16 orang (Gambar 3). Pada kategori rendah, hal ini disebabkan karena nelayan tidak pernah mengikuti pelatihan keselamatan di kapal dan tidak paham mengenai pentingnya alat keselamatan di kapal, serta tidak menganggap berbahaya pekerjaan menangkap ikan, dan pergi melaut hanya untuk sekedar memenuhi kebutuhan perekonomian. Kemudian untuk kategori sedang disebabkan karena nelayan sudah paham tentang arti penting alat keselamatan kerja dan keselamatan di laut, tetapi kesadaran terhadap kecelakaan yang akan terjadi masih dianggap remeh karena pekerjaannya dianggap tidak terlalu berbahaya. Untuk kategori tinggi menjelaskan bahwa, nelayan sudah paham dan memiliki pengalaman kerja yang cukup lama di bidang tersebut. Sehingga timbul kesadaran akibat dari pengalaman kerja yang terkadang mengalami kecelakaan seperti orang jatuh ke laut, terluka pada saat pengoperasian alat tangkap dan kondisi laut yang kurang bersahabat, namun umumnya pengalaman tersebut hanya sekedar menjadi sebuah pengalaman. Selain itu crew kapal menganggap bahwa tanggung jawab terkait ketersediaan aspek keselamatan adalah tugas dari pemilik kapal.

\section{KESIMPULAN}

Kesimpulan yang diperoleh yaitu:

1) Penerapan aturan pengawakan kapal untuk ukuran $<24 \mathrm{~m}$, yaitu nahkoda harus memiliki ANKAPIN II dan KKM memiliki ATKAPIN II hanya 1 kapal yang hampir sesuai, sedangkan yang lain hanya berupa SKK dan BST

2) Kelengkapan aspek keselamatan sudah ada yang menerapkannya, namun belum secara menyeluruh dan didasari pemahaman yang jelas.
3) Pemahaman nelayan terhadap aspek keselamatan kerja untuk kategori ukuran rendah di pangkalan $\mathrm{X}$ yaitu sebanyak 11 orang, sedang 13 orang dan tinggi sebanyak 6 orang, sedangkan pangkalan Y ukuran rendah 12 orang, sedang 22 orang dan tinggi 16 orang.

\section{DAFTAR RUJUKAN}

Budiman S.M; Iskandar B. H; Seboer D. A. 2016. Penataan Sertifikasi Kompetensi Awak Kapal Penangkap Ikan Di Indonesia. Jurnal Teknologi Perikanan dan Kelautan Vol. 7 No. 2 November 2016: 146-152. ISSN 2087-4871.

Food and Agriculture Organization, 2007. Text Convention Works in Fishing Sector. Provisional Record No.12A. Ninety-sixth Session. Geneva. Swiss.

Peraturan Pemerintah Republik Indonesia Nomor 7 Tahun 2000 Tentang Kepelautan.

Peraturan Menteri Perhubungan KM 9 Tahun 2005 Tentang Pendidikan, Pe-latihan, Ujian dan Sertifikasi Pelaut Perikanan

Peraturan Menteri Kelautan dan Perikanan Republik Indonesia Nomor 42/Permen-Kp/2016. Tentang Perjanjian Kerja Laut Bagi Awak Kapal Perikanan.

Undang-Undang No 45 tahun 2009. Tentang Perikanan 